EPiC Series in Engineering
Volume 3, 2018, Pages 2196-2203
HIC 2018. 13th International
Conference on Hydroinformatics

\title{
Comparison of 1DH and 2DH Mathematical Models for Modelling Wave Hydrodynamics in Ofir Beach
}

\author{
Bárbara Vieira ${ }^{1 *}$, José Pinho ${ }^{1}$ and Luís Vieira ${ }^{1}$ \\ ${ }^{1}$ Centre for Territory, Environment and Construction, Department of Civil Engineering, \\ University of Minho, Campus of Gualtar, 4710-057 Braga, Portugal \\ barbaravasquezvieira@gmail.com
}

\begin{abstract}
Coastal zone protection is a very crucial issue in order to defend populations and infrastructures as well as to environment conservation. Adequate tools must be tested and implemented for supporting engineering solutions to face this challenge. In this study, $1 \mathrm{DH}$ and 2DH models were applied to simulate wave hydrodynamics at Ofir beach, NW Portugal. For this purpose, COULWAVE (1DH) and BOUSS-2D (2DH) models were implemented considering both the presence of a detached breakwater and natural conditions aiming the study of the impact of these structures on the significant wave height and the wave energy. A comparison of the performance of the two models was also developed. The methodology adopted in this research work, where a generalised methodology of models applications was used, allows its replication to other coastal stretches being this application dependent on local environmental conditions.
\end{abstract}

\section{Introduction}

Estuarine and coastal zones are highly dynamic systems that are vulnerable to natural and anthropogenic hazards [1] [2], and that require strategies to deal with land subsidence, sea level rise and the increasing risk of storm-surge-induced floods due to frequent extreme weather events [3]. Projections presented by the Intergovernmental Panel on Climate Change (IPCC) indicate that global climate change may rise sea level as much as one meter over the next century and, in some areas, increase the frequency and severity of storms that can result in the retreat of beaches and the rupture of protective structures threatening lives, buildings, and infrastructures [4] [5].

\footnotetext{
${ }^{*}$ Corresponding author
} 
Since coastal areas are home to the majority of the world's largest cities and that these will continue to expand rapidly over the next century because they are a much-appreciated environment by society that supports a large amount of activities and leisure [6], adequate responses in order to minimize impacts are required.

A number of mathematical models based on different assumptions, which limit the types of problems to which they can be applied, have been developed to simulate the propagation and transformation of waves in coastal regions and harbours [7]. This study aims to apply hydroinformatic tools on a coastal zone highly vulnerable to erosion to simulate the influence of a detached breakwater in wave hydrodynamics by analysing and comparing the different performances between two different software solutions for significant wave and wave energy dissipation: Cornell University Long and intermediate WAVE (COULWAVE) and BOUSS-2D.

\section{Material and methods}

\subsection{Study area}

Mathematical modelling for determining the hydrodynamics behaviour for the Ofir beach coast (County of Esposende in Portugal) was applied. The selected study area coincides with the stretch located between the North and South groins, where the Ofir towers (three residential buildings) are located (Figures 1a) and 1b)). Due to Hercules storm early 2014 the Ofir beach was compromised putting at risk the Ofir towers (Figure 1c)). Given this and other historical events and the vulnerability to erosion of this beach, it was considered relevant to study the potential influence of an additional defence structure like a detached breakwater in this coastal segment comparing the results obtained from two software solutions [8] to assess the performance of that defence solution.

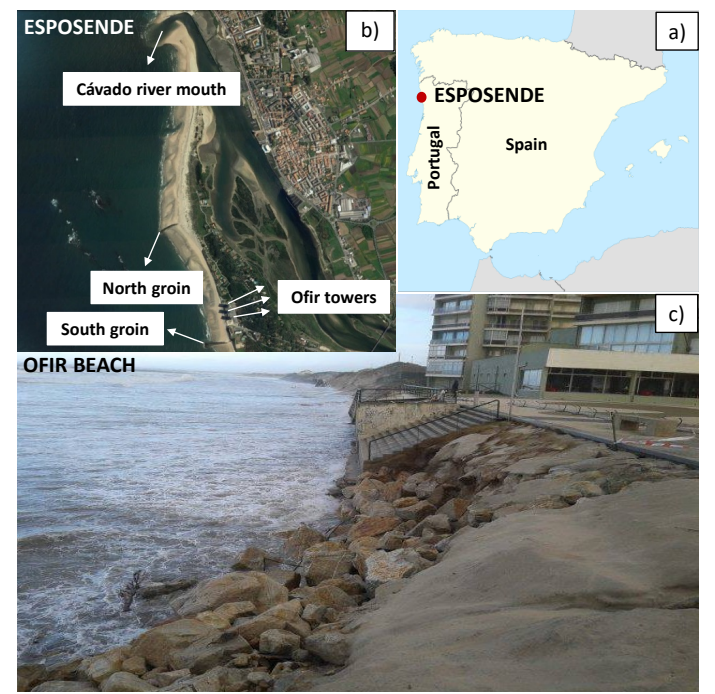

Figure 1: a) Study site; b) Detailed Ofir beach aerial view; c) Erosion problems in Ofir beach (2014 storm)

\subsection{Field data collection}

After performing a field survey using DGPS equipment at Ofir beach and recurring to other bathymetric data sources made available by the Portuguese Hydrographic Institute (IH), ArcGIS was 
used to merge this information and to create the actual beach morphology. This morphology was used to interpolate the necessary bathymetry of the $2 \mathrm{DH}$ model and define beach profiles used in the $1 \mathrm{DH}$ model. The design of the detached breakwater follows the UK Department of Environment Food and Rural Affairs [9] methodology and the wave data was collected at IH monitoring stations for a time period between 1993 and 2007.

\subsection{COULWAVE and BOUSS-2D models}

COULWAVE (1DH) is a free surface wave model that has been applied to a wide variety of problems like wave run-up, and wave generation by underwater landslides, among many others. It solves depth-integrated long-wave based equation models, including the nonlinear shallow water wave equations and a number of the weakly dispersive Boussinesq-type equations. The COULWAVE allows simulating wave transformation phenomena in varying depth bottoms, since it includes refraction due to currents, run-ups and non-linear interactions of higher order [10]. This model uses the concept of "multi-layer" approach for the integration of the primitive equations of motion (continuity and momentum equations) where the water column is divided into several layers [11]. Each layer can consider a given velocity profile. The accuracy of the developed model depends upon the number of layers that is considered, allowing its use in very deep waters [8].

BOUSS-2D is a comprehensive numerical model for simulating the propagation and transformation of waves in coastal regions and harbours based on a time-domain solution of Boussinesq-type equations. The governing equations (continuity and momentum equations) in BOUSS-2D are solved in time domain with a finite-difference method where the water-surface elevation and horizontal velocities are calculated at the grid nodes in a staggered manner [12] [13]. The equations are depth-integrated equations for nonlinear waves propagating in shallow and intermediate water depths that can simulate most of the hydrodynamic phenomena of interest in coastal regions and harbour basins including: shoaling; refraction; diffraction; full/partial reflection and transmission; bottom friction; nonlinear wave-wave interactions; wave breaking and run-up; wave-induced currents; wave-current interaction. Fully nonlinear equations by Nwogu [13] are able to implicitly model the effects of wave-current interaction. Currents can either be introduced through the boundaries or by explicitly specifying a current field.

In order to compare and discuss obtained results from the analysis of COULWAVE and BOUSS2D models at equivalent observation points positions, for the study area both numerical models were set to the same incident wave height, period, and simulation conditions. The choice of the boundary conditions was imperative to allow the models to best match each other and the domains were defined considering the need to provide sufficient time and distance for the waves to interact with each other ensuring wave propagation with proper velocities and wave heights. Since the bathymetric samples resolution was about $4.2 \mathrm{~m}$, for the $1 \mathrm{DH}$ model a grid size of $\Delta \mathrm{x}=4.2 \mathrm{~m}$ was adopted. For this simulation, it was considered: (i) fully-nonlinear equations to allow larger amplitudes for the simulation of waves, (ii) a finite difference scheme to the second order $\left(\Delta x^{2}\right)$ in space for its accuracy; (iii) a wave type defined by a spectrum of amplitudes; (iv) and a wave breaking model to avoid overflow. In BOUSS-2D model, the grid domain is about $1150 \times 1816 \mathrm{~m}$ (x,y) exceeding the Ofir beach limits in order to avoid interference of values imposed at these boundaries, and its angle is $0^{\circ}$. During the generation of the grid it was necessary to define the cell size so as the depth interpolation and extrapolation. In order to reduce some calculation time, and because it is a large domain, it was defined a $10 \times 10 \mathrm{~m}$ cell size. The wave maker was placed far enough from shore to avoid interaction between the wave maker and reflecting waves since the external boundary behind the wave maker is treated as a vertical wall and it was also enabled a wave breaking model which allows dissipating wave energy.

Table 1 synthetizes adopted simulations conditions and parameters values for each model. 


\subsection{Simulated scenarios}

Variables for COULWAVE model input were: significant wave height $\left(\mathrm{H}_{\mathrm{s}}\right)$ and period $(\mathrm{T})$ to define wave spectrum; breakwater crest level $\left(h_{c r}\right)$; and the distance from shore to the detached breakwater (X). For the BOUSS-2D model input variables were the same as the COULWAVE model with an additional consideration for the wave direction $\left(^{\circ}\right)$ and the detached breakwater length (L). From the design methodology followed for the detached breakwater and from wave data analysis, the adopted values were: $\mathrm{H}_{\mathrm{s}}=6.64 \mathrm{~m} ; \mathrm{T}=9.30 \mathrm{~m} ; \mathrm{h}_{\mathrm{cr}}=2.70 \mathrm{~m} ; \mathrm{X}=235 \mathrm{~m}$; wave direction $=270^{\circ} ; \mathrm{L}=470 \mathrm{~m}$. For both $1 \mathrm{DH}$ and $2 \mathrm{DH}$ the results obtained were registered by the same probes at six different locations in each models' domain (before and after the detached breakwater) giving as output time series of the significant wave heights. After the calculation of wave energy separately (Equation 1) in order to assess the influence of the detached breakwater on significant wave height and wave energy at those locations it was selected every maximum output result at each of those points.

$$
\mathrm{E}=1 / \mathrm{g}\left(\rho \mathrm{gH} \mathrm{H}^{2}\right)
$$

where: $E$ is the wave energy per unit area $\left(J / \mathrm{m}^{2}\right), \rho$ is the water density $\left(\mathrm{kg} / \mathrm{m}^{3}\right), \mathrm{g}$ is the gravity acceleration $\left(\mathrm{m} / \mathrm{s}^{2}\right)$ and $\mathrm{H}$ is the wave height $(\mathrm{m})$. For this calculation it was considered a $\rho_{\text {sea }}$ water $=$ $1025 \mathrm{~kg} / \mathrm{m}^{3}$ and $\mathrm{g}=9.81 \mathrm{~m} / \mathrm{s}^{2}$.

\begin{tabular}{|c|c|c|c|}
\hline \multicolumn{2}{|c|}{ MODELLING CONDITIONS } & COULWAVE & BOUSS-2D \\
\hline \multicolumn{2}{|c|}{$\begin{array}{l}\text { Wave height }(\mathrm{m}) \text { considered from } \\
\text { data analysis }\end{array}$} & 6.64 & 6.64 \\
\hline \multicolumn{2}{|c|}{$\begin{array}{l}\text { Wave period (s) considered from } \\
\text { data analysis }\end{array}$} & 9.30 & 9.30 \\
\hline \multicolumn{2}{|l|}{ Wave type } & Wave spectrum & Regular \\
\hline \multicolumn{2}{|l|}{ Spectrum type } & TMA & JONSWAP (only option) \\
\hline \multicolumn{2}{|c|}{ Wave maker location (m) } & 60.0 & 0.0 \\
\hline \multicolumn{2}{|c|}{$\mathrm{xx}$ domain $(\mathrm{m})$} & 934.8 & 1150.0 \\
\hline \multicolumn{2}{|l|}{ yy domain (m) } & --- & 1816.0 \\
\hline \multicolumn{2}{|c|}{ Time simulation (s) } & 200.0 & 200.0 \\
\hline \multirow{6}{*}{$\begin{array}{l}\text { Observation } \\
\text { points } \\
\text { location }(\mathrm{m})\end{array}$} & Position 1 & 90.0 & 90.0 \\
\hline & Position 2 & 360.0 & 360.0 \\
\hline & $\begin{array}{l}\text { Position } 3 \\
\text { (near crest) }\end{array}$ & 488.0 & 488.0 \\
\hline & Position 4 & 650.0 & 650.0 \\
\hline & Position 5 & 800.0 & 800.0 \\
\hline & Position 6 & 870.0 & 870.0 \\
\hline \multirow{4}{*}{ Boundaries } & Left & $\begin{array}{l}\text { With sponge layer } \\
\text { (reflective) }\end{array}$ & Wave maker \\
\hline & Right & $\begin{array}{l}\text { Without sponge layer } \\
\text { (reflective) }\end{array}$ & Reflective \\
\hline & Top & --- & $\begin{array}{l}\text { Width: } 50.0 \mathrm{~m} \\
\text { Value: } 1.0\end{array}$ \\
\hline & Bottom & -- & $\begin{array}{l}\text { Width: } 50.0 \mathrm{~m} \\
\text { Value: } 1.0\end{array}$ \\
\hline \multicolumn{2}{|c|}{ Courant number } & $\begin{array}{l}0.3 \text { (recommended for } \\
\text { fully nonlinear) }\end{array}$ & 0.6 (recommended) \\
\hline \multicolumn{2}{|c|}{ Spacing/Cell dimension (m) } & 4.2 & $10.0 \times 10.0$ \\
\hline \multicolumn{2}{|c|}{ Wake breaking model } & Yes & Yes \\
\hline \multicolumn{2}{|l|}{ Time step (s) } & 1.0 (recommended) & 0.41 (recommended) \\
\hline
\end{tabular}

Table 1: Modelling conditions for COULWAVE and BOUSS-2D models. 
Results are presented for two different scenarios: i) actual beach conditions and ii) considering a detached breakwater placed 235 meters from the coastline. Significant wave height and wave energy results obtained with the $1 \mathrm{DH}$ and $2 \mathrm{DH}$ models were compared for similar wave conditions.

\section{Results and Discussion}

For both models the significant wave height was recorded for a simulation period of 200 seconds at six observation points. Figures 2 and 3 depict the COULWAVE and BOUSS-2D model domain, respectively, with the location of the six observation points, and significant wave heights results. Figures 4 and 5 provide the maximum significant wave heights and the maximum wave energy for the two established scenarios, respectively, registered by the probes at each observation point, showing that is slightly obvious the difference between the results of both models. A standard deviation examination obtained for each model demonstrated an evidence of smaller values at most observation points in the COULWAVE model, indicating that the data points tend to be closer to the mean comparing to the BOUSS-2D.

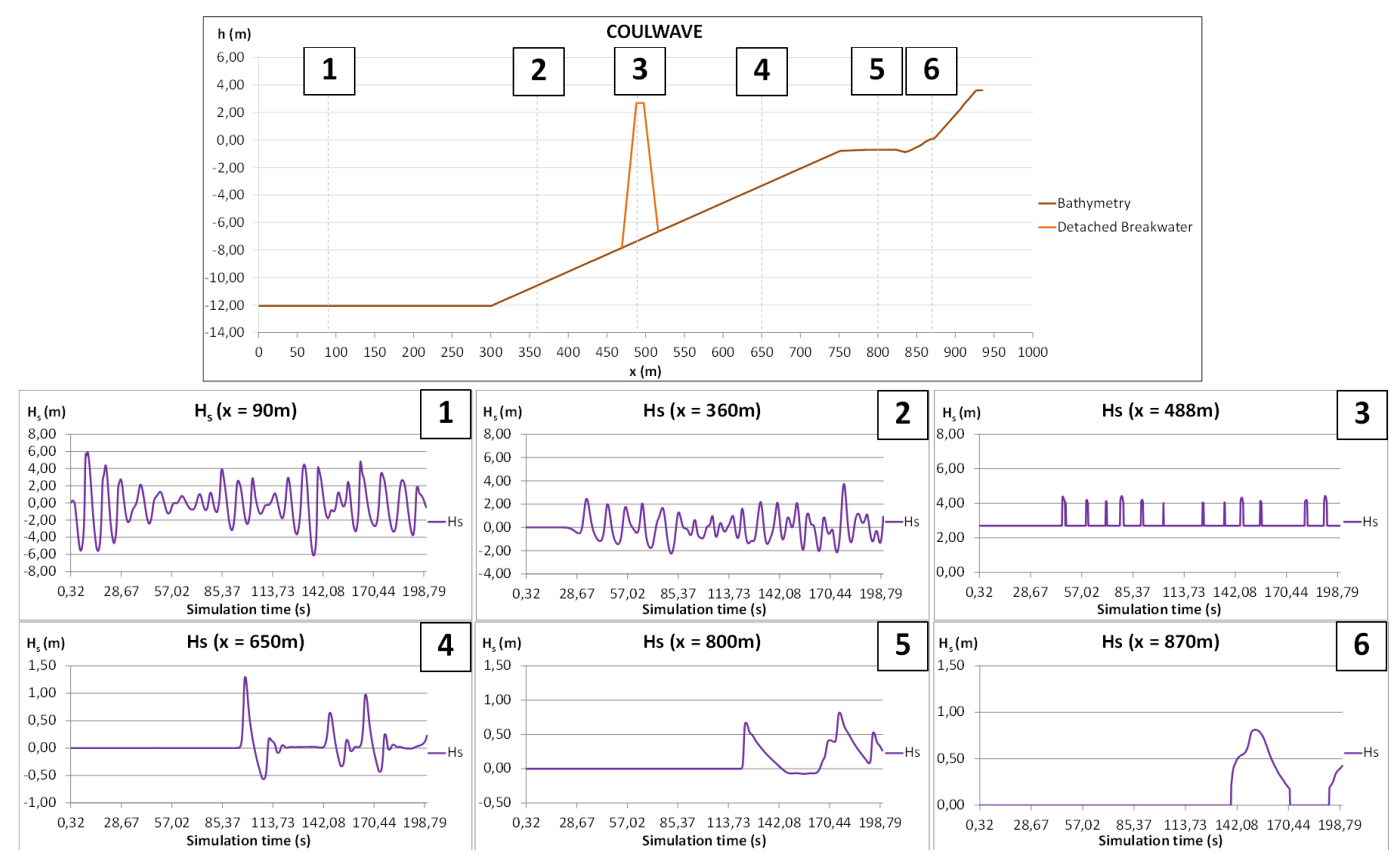

Figure 2: COULWAVE simulation results for significant wave height (scenario with a detached breakwater).

Differences in terms of significant wave height results for both models may be influenced by the different wave makers and their locations (left boundary conditions). It is verified that the significant wave heights in BOUSS-2D only start being registered approximately 42 seconds after the simulation began because of the wave maker not being near Probe 1. Analysing the results at the observation points it can be concluded that: (i) regarding maximum significant wave heights for both models there are no significant differences in the results between models except at Position $3\left(\mathrm{H}_{\mathrm{s}} \sim 4 \mathrm{~m}\right.$ for COULWAVE and $\mathrm{H}_{\mathrm{s}} \sim 3 \mathrm{~m}$ for BOUSS-2D) and at Position $6\left(\mathrm{H}_{\mathrm{s}} \sim 0.75 \mathrm{~m}\right.$ for COULWAVE and $\mathrm{H}_{\mathrm{s}} \sim$ $1.25 \mathrm{~m}$ for BOUSS-2D); (ii) regarding minimum significant wave heights there are only noticeable differences in the results between models before the detached breakwater (Positions 1, 2 and 3). In 
addition, the slight difference of results may also be explained by differences in default values of parameters applied in COULWAVE and BOUSS-2D.

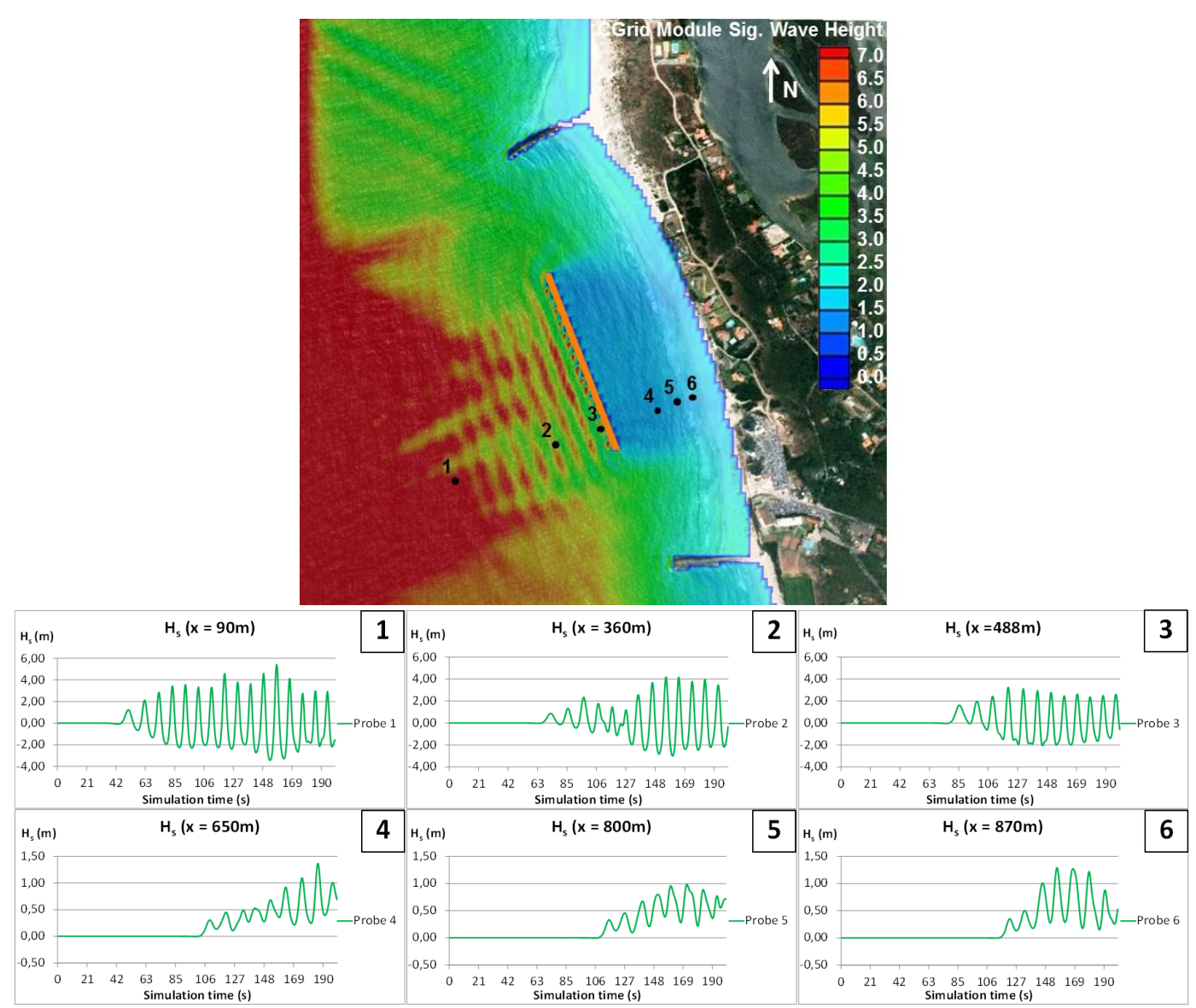

Figure 3: BOUSS-2D simulation results for significant wave height (scenario with a detached breakwater).

Regarding the influence of the detached breakwater on the significant wave heights it is safe to say that both models show a positive impact by reducing the significant wave height when comparing to the actual beach conditions (without a detached breakwater). This influence is explicitly observable between Position 3 (without the detached breakwater) and Position 4 (with the detached breakwater) where the significant wave height is reduced by more than half of its original significant wave height (from $\mathrm{H}_{\mathrm{s}} \sim 4 \mathrm{~m}$ to $\mathrm{H}_{\mathrm{s}} \sim 1.5 \mathrm{~m}$ for both COULWAVE and BOUSS-2D). At Positions 5 and 6 it is also noticeable this effect. In general, both models presented similar simulation results for significant wave heights only with slight differences at the Positions 1,5 and 6 for the scenario without a detached breakwater. In relation to wave energy (because it dependents on significant wave height) the same conclusions about the influence of the detached breakwater are valid. 


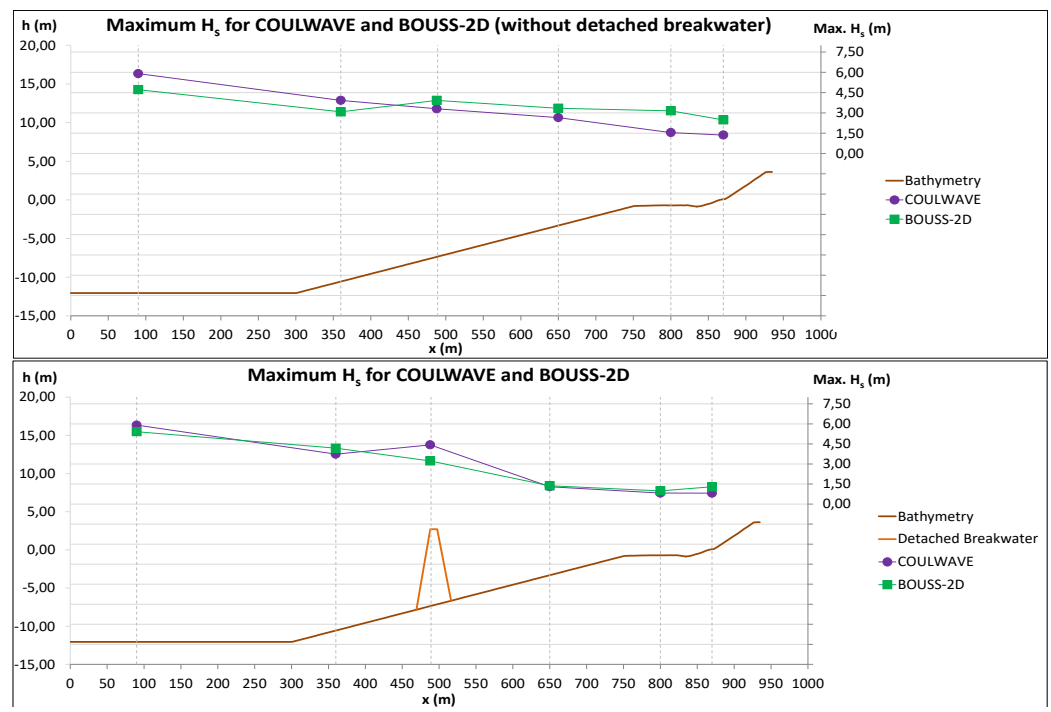

Figure 4: Comparison of results for maximum significant wave heights registered by the probes.

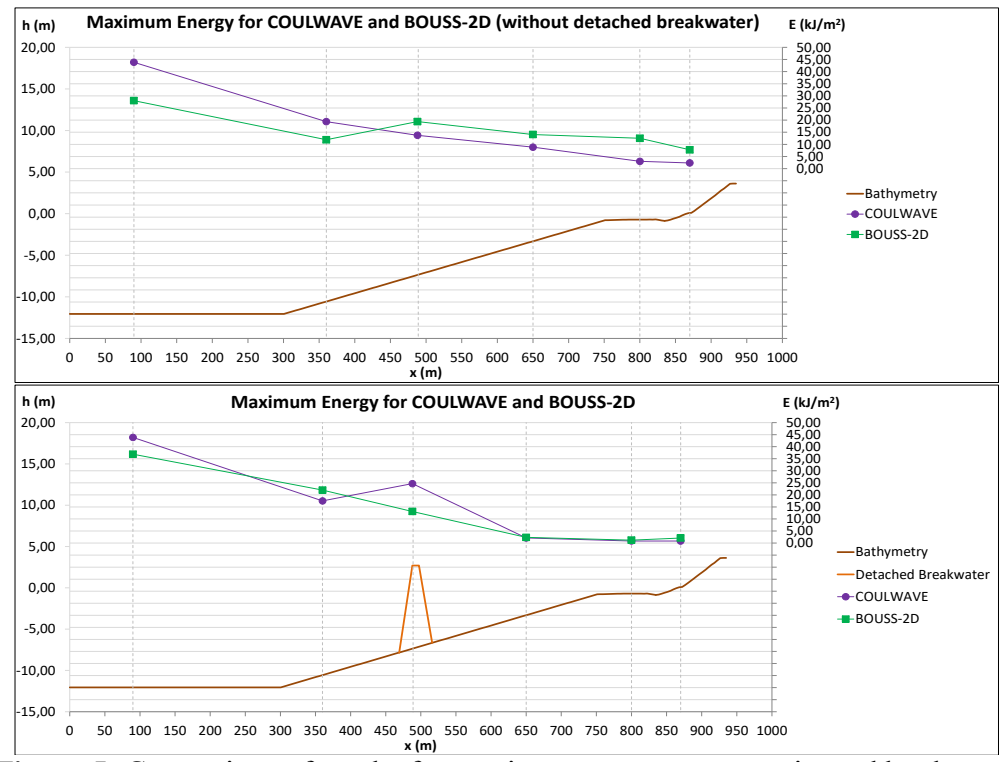

Figure 5: Comparison of results for maximum wave energy registered by the probes.

\section{Conclusions}

Both implemented models are based on depth-integrated Boussinesq type equations for the conservation of mass and momentum for nonlinear waves propagating in shallow and intermediate water depths. Good results were obtained applying COULWAVE and BOUSS-2D models in the analysis of a detached breakwater effects on the significant wave height and wave energy. For a significant wave height analysis it is evident that the detached breakwater has a substantial impact in decreasing the significant wave height and consequently the wave energy as depicted at Positions 3 (without the detached breakwater) and Position 4 (with the detached breakwater). Although 
COULWAVE model provides more irregular waves relatively to BOUSS-2D model and the significant wave heights in BOUSS-2D only start being registered approximately 42 seconds after the simulation began, it was concluded that slight differences in maximum significant wave heights are observed with COULWAVE which could mean that this model appears to be more accurate than BOUSS-2D due to smaller values for standard deviation and because of its more complete mathematical formulation that allows simulating non-linear effects in wave propagation. These differences are noticeable at the Positions 1, 5 and 6 for the scenario without a detached breakwater and at the Positions 3 and 6 for the scenario with a detached breakwater. Regarding minimum significant wave heights there are only noticeable differences in the results between models before the structure. Due to the models' domain, calculation time (for the same time simulation) was longer for BOUSS-2D taking 44 seconds and 36 seconds for the scenarios with and without a detached breakwater, respectively, while for the COULWAVE model it only took approximately 6 seconds for both scenarios.

\section{References}

[1] J. Weinberg, "The Big Squeeze: Coastal megacities face growing pressure from sea and land," Stockholm Waterfront, no. 1, Stockholm, pp. 5-7, 2015.

[2] P. Narra, C. Coelho, F. Sancho, and J. Palalane, "CERA: An open-source tool for coastal erosion risk assessment," Ocean Coast. Manag., vol. 142, pp. 1-14, 2017.

[3] IPCC, Managing the Risks of Extreme Events and Disasters to Advance Climate Change Adaptation. Special Report of working groups I and II of the Intergovernamental Panel on Climate Change. Cambridge, UK: Cambridge University Press, 2012.

[4] J. Gilbert and P. Vellinga, Climate Change: The IPCC Response Strategies - Chapter 5. Report prepared for Intergovernmental Panel on Climate Change by Working Group III 330 pp, Digitized by the Digitization and Microform Unit (2010), UNOG Library, 1990.

[5] N. Rangel-Buitrago, V. N. de Jonge, and W. Neal, "How to make Integrated Coastal Erosion Management a reality," Ocean Coast. Manag., no. January, pp. 0-1, 2018.

[6] B. Castelle et al., "Spatial and temporal patterns of shoreline change of a 280-km high-energy disrupted sandy coast from 1950 to 2014: SW France," Estuar. Coast. Shelf Sci., vol. 200, pp. 212-223, 2018.

[7] O. G. Nwogu and Z. Demirbilek, "BOUSS-2D: A Boussinesq wave model for coastal regions and harbors. Theoretical Background and User's Manual, U.S. Army Corps of Engineers," Washington, DC, USA, 2001.

[8] B. F. V. Vieira, "Wave hydrodynamics in coastal stretches influenced by detached breakwaters," MSc Thesis, University of Minho, 2014.

[9] DEFRA, "Department for Environment Food and Rural Affairs - Guidance for outline design of nearshore detached breakwaters on sandy macro-tidal coasts," Environment Agency of United Kingdom, 2010.

[10] P. R. F. Teixeira, C. J. Fortes, L. V. Pinheiro, and T. Okamoto, "Análise comparativa dos modelos não-lineares COULWAVE e BOUSS3W aplicados à simulação da rebentação," in $I V$ SEMENGO - Seminário e Workshop em Engenharia Oceânica, Rio Grande, RS, Brazil, 2010.

[11] P. J. Lynett and P. L.-F. Liu, Modeling wave generation, evolution, and interaction with depth-integrated, dispersive wave equations. COULWAVE Code Manual. Cornell University Long and Intermediate Wave. Modeling Package. USA, 2014.

[12] O. G. Nwogu, "Alternative Form of Boussinesq Equations for Nearshore Wave Propagation," J. Waterw. Port, Coastal, Ocean Eng., vol. 119, no. 6, pp. 618-638, Nov. 1993.

[13] O. G. Nwogu, "Numerical Prediction of Breaking Waves and Currents with a Boussinesq Model," in 25th International Conference on Coastal Engineering, 1996, pp. 4807-4820. 